\title{
Entre la flânerie y el ostracismo: la resignificación subjetiva de la ciudad en Fabián Casas y Martín Gambarotta
}

\author{
Carlos Hernán SosA \\ Universidad Nacional de Salta \\ chersosa@hotmail.com
}

\begin{abstract}
RESUMEN
Desde los estudios pioneros de Walter Benjamín dedicados a la imagen del flâneur en la poesía de Baudelaire, la experiencia del sujeto poético y su íntima reconstrucción afectiva de la ciudad constituyen un índice significativo para aproximarnos a la experiencia de la vida moderna. En este artículo, nos interesa revisar cuáles son las particularidades que distinguen esta experiencia en un corpus de poesía argentina reciente -los libros Punctum y Refrito, de Martín Gambarotta, y Horla City y otros, de Fabián Casas-, que durante las décadas de 1990 y 2000 tematiza, con insistencia y mediante opciones diversas, la relación sujeto-ciudad. En dichos textos, es posible releer una continuidad -relativamente canónicadel paseante por los márgenes periféricos de la modernidad -en el caso de Casas- y la reclusión voluntaria, como repliegue extremo ante la vivencia del deambular callejero, que se percibe como intimidante en Gambarotta.
\end{abstract}

Palabras clave: Poesía argentina reciente, ciudad, Buenos Aires, flâneur, modernidad latinoamericana.

Between the flanerie and the ostracism: the subjective resignification of the city in Fabián Casas and Martín Gambarotta

\begin{abstract}
Since the pioneering studies of Walter Benjamin about to image the flâneur in the poetry of Baudelaire, the poetic subject's experience and their intimate emotional reconstruction of the city constitute a significant index to approach the experience of modern life. In this article, we want to check what are the particularities that distinguish this experience in the recent Argentine poetry -specially in the books Punctum and Refrito, by Martín Gambarotta, and Horla City y otros, by Fabián Casas-, than during the 1990-2000 decades, insistently and using various options, the relationship subject-city. In these texts, it's possible to read the continuity -relatively canonical- of the flaneur by peripheral margins of modernity -in the case of Casas- and the voluntary seclusion, as extreme withdrawal before the experience of the street wandering, perceived as intimidating in Gambarotta.
\end{abstract}

Key words: Argentine recent poetry, city, Buenos Aires, flâneur, Latin American modernity. 
Los que llegan en avión se sorprenden por lo que ha crecido año tras año la ciudad: el cordón industrial el cordón policial, el cordón umbilical, la alquimia del verso. Fabián Casas, "Desde el aire".

En Crimen y castigo, de Fedor Dostoievski, Raskólnikov -como un autómata enfebrecido por el odio- atraviesa de manera indolente la maraña urbana de San Petersburgo, amojonada por avenidas, canales, puentes, mercados y tabernas, mientras cuenta los 730 pasos que separan la miserable buhardilla que habita en un edificio de departamentos de la habitación de la usurera a quien va a asesinar.

En La Taberna de Émile Zola, Gervaise Macquart no puede evitar conmoverse ante el edificio que ocupará como residencia en la periferia de París. Como un ser vivo amenazador, la altura impactante de la construcción, la agitación envolvente de las personas que lo habitan y la invasión de los olores provenientes de las habitaciones generan tal impacto que la mujer - recién llegada a la ciudad- se detiene azorada ante el espectáculo, como si pidiese permiso antes de entrar.

En "El hombre de la multitud", de Edgar Allan Poe, el narrador persigue a un anciano por el hormigueante deambular de las calles de Londres. En un estado enrarecido, bajo una sensibilidad exacerbada que lo lleva a acechar a hurtadillas al desconocido, el narrador padece -como víctima de la fascinación y el rechazo ante los innumerables rostros que va sorteando- la experiencia intimidante del contacto con la muchedumbre anónima y oscilante.

En cada una de estas escenas paradigmáticas, que aquí repasamos sucintamente, la literatura ha dejado registrado un modo de asumir la experiencia de la vida moderna en el mundo occidental. La desconfianza ante lo desconocido, la exhibición desacralizadora de lo privado, los juegos de seducción que regala el anonimato y la peligrosidad de la muchedumbre son índices complementarios de una crisis de la subjetividad, cuya integridad se siente perturbada por el nuevo vértigo que impone la vida en las grandes ciudades desde mediados de siglo XIX. Sin dudas, los estudios siempre incitantes de Walter Benjamín (2012) dedicados a la imagen del flâneur, al paseante urbano, en la poesía de Charles Baudelaire, son los que han retratado con mayor precisión las ambivalencias traumáticas que afectan, en este caso, al sujeto poético en su íntima reconstrucción afectiva dentro del perímetro -seductor y amenazante- que impone el escenario urbano. 
Cuando se revisa la producción poética de comienzos de siglo XXI, asombra la constancia de algunas problemáticas, evidentemente ya topicalizadas en el terreno literario, que continúan tensionando las formas de representación del sujeto poético en la ciudad, resemantizando algunas de las variables de la discursividad literaria decimonónica que acabamos de señalar. Si como en nuestro caso el corpus abarca producciones gestadas en ámbitos periféricos como el latinoamericano, parecería inadecuado o insuficiente seguir pensando la experiencia de la modernidad en sintonía con el proceso vivido en las metrópolis europeas -y sus representaciones discursivas ad hoc- ${ }^{1}$ en el sentido de que tal como ha sido interpretado desde diversos encuadres -por Antonio Cornejo Polar (1994), Ángel Rama (1985a y 1985b) o Julio Ramos (1989), entre otros- el proceso de modernización en Latinoamérica responde a variables lo suficientemente particulares para demandar una comprensión propia y diferenciada.

En las últimas décadas, la discusión sobre esta problemática continúa apostando por conceptualizaciones y modelos de interpretación propios, que resultan más idóneos. Así, por ejemplo, la imposición globalizada de un discurso sobre la posmodernidad, que tuvo notable presencia en la agenda de discusiones académicas durante las décadas de 1980 y 1990, se ensombrece ante la situación peculiar de Latinoamérica. En este sentido, y siguiendo la recuperación que realiza Alejandra Nallim (2012), de una propuesta previa concebida por Nicolás Rosa, resulta productivo repensar estas experiencias vinculadas a la modernización sociocultural en Latinoamérica en términos de transmodernidad: «Latinoamérica no es premoderna, ni moderna ni tampoco posmoderna, sino que "ha aceptado y reelaborado sucesivas etapas de modernización occidental y las encauza en su propio ideario ético e histórico"» (Nallim, 2012: 23). Estas propuestas, gestionadas desde la propia crítica cultural latinoamericana, nos brindan la alternativa de interpretar la recurrencia sobre el sujeto poético y su experiencia compleja en las ciudades latinoamericanas, a partir de las aristas específicas de los procesos sociohistóricos de la región y la conformación de nuestras idiosincrasias cultuales distintivas.

En el caso de la producción lírica de Buenos Aires, durante las décadas de 1990 y 2000 se ha tematizado, con insistencia y mediante opciones diversas, la relación sujeto(s)-ciudad(es). En este tratamiento, precisamente, se han subrayado aspectos representativos que parecen responder a circunstancias satelitales al modo en que Latinoamérica ha ido gestionando sus escarceos de acercamiento y distanciamiento de los procesos de modernización sociocultural: la marginalidad inconmovible de los asentamientos urbanos, las manifestaciones polifuncionales de la cultura

\footnotetext{
${ }^{1}$ Para este punto, sigue siendo importante la lectura, siempre sugestiva, del estudio que Marshall Berman (1999) ha dedicado al análisis de la experiencia de la modernidad occidental.
} 
popular, la dislocación extrañada del migrante afincado en la urbe, la presencia paradójica de la tecnología como compañera fantasmagórica de la pobreza extrema o el delito como capa impregnante de un discurso que oscila entre el espíritu contestatario y la vacuidad de la pose crítica. ${ }^{2}$ Considerando estos presupuestos, en este artículo me interesa revisar cuáles son las particularidades que distinguen las representaciones poéticas de la experiencia vivida en Buenos Aires, en un corpus integrado por los libros Punctum (1996) y Refrito (2009), ${ }^{3}$ de Martín Gambarotta, y Horla City y otros $(2010)^{4}$ de Fabián Casas, donde es posible releer una continuidad -relativamente canónica- del paseante por los márgenes periféricos urbanos -en el caso de Casas- y la reclusión voluntaria, como repliegue extremo ante la vivencia del deambular callejero, que se percibe como experiencia intimidante o prescindente en Gambarotta.

Tanto en su obra poética, más sostenida en el tiempo, como también en sus dos publicaciones narrativas donde se recogen relatos -Ocio (2002) y Los Lemmings y otros (2005)-, Fabián Casas ha construido una mitología personal de filigrana con el barrio porteño de Boedo, al cual incluso le ha dedicado un libro cuyo título evoca explícitamente su genealogía baudeleriana: El Spleen de Boedo (2003). De calibre literario semejante es el enunciador apoteótico de la urbanidad que asume sus textos, depositario tardío de una tradición donde se amalgaman facetas caleidoscópicas: el flâneur nocturno, el muchacho de barrio, el voyeur de balcón, el poeta escéptico con la crítica literaria, el pensador levemente desmitificador de la historia nacional, el gozador de la vida y sus estimulantes ad hoc (el alcohol, las drogas, el sexo) que resucitan una imagen desnutrida de los paraísos artificiales decimonónicos. El universo que estos poemas privilegian para la praxis citadina del enunciador es el de la noche de Buenos Aires, el del asfixiante deambular cuando el calor impide el sueño, tal como se despliega por ejemplo en la experiencia agobiante recogida en "Brasas":

Toda la noche caminando sobre brasas

y a lo lejos las puertas de los autos

que se cierran de un golpe.

${ }^{2}$ Una presentación cagada de hipótesis productivas, desde una perspectiva de análisis sociocultural, y que resulta iluminadora para pensar la poesía porteña de las últimas décadas, puede encontrarse en el trabajo de Beatriz Sarlo (2009).

${ }^{3}$ Refrito (2009) es una reedición, que incluye varias reescrituras, de otros dos libros de Martín Gambarotta posteriores a Punctum (1996); ellos son: Seudo (2000) y Relapso+Angola (2005). Hasta el momento, el último libro publicado por Gambarotta es Para un plan primaveral, que fue editado durante el año 2011.

${ }^{4}$ Bajo el título Horla City y otros. Toda la poesía 1990-2010 (2010) se reúnen todos los libros de poemas publicados por Fabián Casas hasta el momento: Tuca (1990), El salmón (1996), Oda (2003), El Spleen de Boedo (2003) y Horla City (2010). 
Estás harto de la comida seriada de los aviones y del doble que crece a costa de tus nervios tratando de conquistar el mundo o metabolizar el día.

Que está extraviado. La buena onda se echó a perder hace una semana.

A los jeans mojados les crecieron hongos. Y las palabras que elaboraste de disculpa son las migas que deja un paranoico para saber cómo volver a casa. (Casas, 2010: 140)

Los versos acumulan signos de una sensación de hastío, de vacío omnímodo, que se hiperboliza con insistencia en los textos de Casas. En una intimidad apenas escrutable, el paseante nocturno manifiesta hasta la alienación su desazón existencial, su spleen remasterizado, para emplear una imagen que sintoniza con la galería de metáforas tecnificadas que repiten los poemarios del autor: como el Delta del Tigre personificado como un scanner que "no puede conectar nada con nada" (Casas, 2010: 133) o la fanática mujer evangelista que aparece "reseteando la biblia en las esquinas" (Casas, 2010: 189). Si la disociación gramatical de la persona es un asomo de la propia incomodidad del yo (asumido como él) que se acentúa, luego, con la expresión esquizofrénica del doble, en el final la paranoia explicita ya sin rodeos la falta de salida, la angustia ante la experiencia no reversible del sosiego perdido, que brota desde el tenebroso recuerdo infantil de aquellas migas de los cuentos de hadas que, lo sabemos todos, serán devoradas por los pájaros para extraviarnos el camino.

La simbiosis entre esta pesadumbre individual y la ciudad es ineludible, no en vano Buenos Aires aparece rebautizada como Horla City, nombre que de manera intertextual recupera el cuento "El Horla" de Guy de Maupassant, donde el protagonista es poseído por un ente fantasmagórico y maligno que finalmente lo enloquece. El Buenos Aires desequilibrado que nos revela Casas se encumbra, entonces, como un monumento de la decadencia personal y colectiva, donde se oferta -como los números perdedores de loterías ya sorteadas- la obsolescencia de lo cotidiano, en un clima de feria donde se comercia al menudeo alicientes fallidos contra la vida embrutecedora de la ciudad:

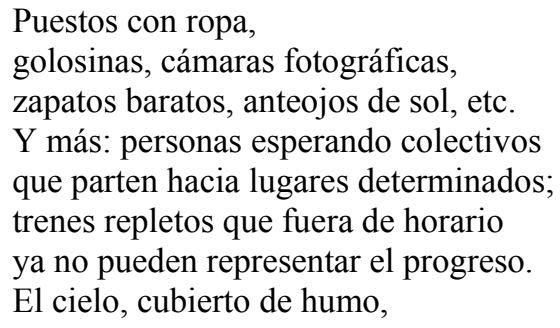


vale menos que la tierra.

Es definitivo,

acá la naturaleza bajó los brazos

o está firmemente domesticada en los canteros. (Casas, 2010: 56)

La imagen de la ciudad, con frecuencia, se disgrega en pequeñas alegorías vencidas de la vida moderna: la velocidad animalizada de los transeúntes en la calle, los ruidos (y los silencios) inhumanos de la urbe que cambia (con la vorágine de las obras en construcción, con el mutismo de las fábricas abandonadas), las barreras de los cruces ferroviarios y sus lentos trenes, la fauna estereotipada de remiseros y taxistas, la telaraña de cables y ropa colgada y la artificialidad convencional de las luces eléctricas diseñan las facetas de un espectáculo continuado y envejecido -como el de los desaparecidos cines barriales en los domingos de matiné-:

La red de nervios de Horla City

expulsa trenes en mal estado

hacia los confines de la provincia.

Hay mujeres policías trabajando en las estaciones, hay evangelistas predicando en las estaciones, ciegos, mutilados, cantantes fracasados, cruzando los andenes.

No se lo pierdan. (Casas, 2010: 176)

Por su parte, bares, parrillas, cines, playas de estacionamiento, parques, estaciones de tren, gimnasios, estadios, subterráneos, discotecas, balnearios se van bosquejando espacialmente a medida que avanza el flâneur porteño, en su desplazamiento por la geografía urbana en la que merodea. En el poema "El parque, a diferentes horas", se superponen variaciones del paseo popular mientras el enunciador, en una clara actitud de impugnación, visualmente disecciona sin piedad a los otros paseantes ocasionales:

Oscurece, y en el centro del parque se prende el esqueleto luminoso de la feria.

Días cortos, con un fondo de viento y lluvia, no paran a los visitantes

que estacionan sus autos sobre las calles laterales.

Como las amistades en cautiverio

de los tours, la gente pasea, habla y se enoja

porque el lago está repleto

de su propios excrementos

y los patos parecen

sachets a la deriva... 
Un sacón negro, 50 pesos.

Camisa floreada, psicodélica, 25.

La prole corre con su nieve artificial

mientras los padres añoran

el verano pasado en el corazón del bronceador.

Recién salidos de la bailanta,

la colonia de jóvenes

se arrastra y se aparea sobre el césped... (Casas, 2010: 91)

La opción de la experiencia subjetiva de los treinta y nueve poemas que integran Punctum (1996), de Martín Gambarotta, parece ubicarse en las antípodas de la flânerie; el espectáculo de la gran ciudad es sustituido por el ostracismo autoimpuesto del protagonista, quien en contadas ocasiones traspasa la puerta de su departamento. La propia genealogía discursiva elegida señala aquí mayor cercanía a los modos de representación de la captación fotográfica, pues el punctum -según Roland Barthes (2012)- es aquel elemento del azar que nos interpela subjetivamente como espectadores de una fotografía. ${ }^{5}$ Subjetividad y estatismo parecen conjugarse, desde un comienzo, como la estrategia de apropiación de los espacios especialmente los cerrados-, de los sujetos -sobre aquellos que pueden atisbarse desde una ventana-, de los azarosos objetos de la ciudad que van cruzándose ante la retina -de significación barthesiana- del protagonista de este poemario.

Cadáver, el personaje excesivamente yacente en su habitación, ve pasar los días embutido en la cama anclada frente al televisor. En su registro personal de la realidad, es decir en las imágenes líricas que estampan los referentes de su entorno, hay que buscar ese punctum que reconstruye una percepción íntima del universo. En esta nueva lectura del destino, vislumbrada desde una resemantización del primoroso estuche burgués -tal como había sido metafóricamente caracterizada la experiencia vital de artista expatriado de la sociedad, por Walter Benjamin (2012)-, puede comprenderse la instancia del aislamiento vital del protagonista de Gambarotta. La reclusión del mundo que vive el personaje es proporcional a la

${ }^{5}$ Roland Barthes (2012) señala dos alternativas de vinculación del observador con la fotografía, a partir de las categorías de studium y punctum. En cuanto a la primera, afirma: "Por medio del studium me intereso por muchas fotografía, ya sea porque las recibo como testimonios políticos, ya sea porque las saboreo como cuadros históricos: pues es culturalmente (esta connotación está presente en el studium) como participo de los rostros, de los aspectos, de los gestos, de los decorados, de las acciones. Mientras que el punctum "viene a perturbar el studium", pues "punctum es también: pinchazo, agujerito, pequeña mancha, pequeño corte, y también casualidad. El punctum de una foto es ese azar que en ella me despunta (pero que también me lastima, me punza)" (Barthes, 2012: 58-59). Subrayado en el original. Un estudio que ha retomado, tempranamente, los aportes teóricos de Barthes (2012) -que aquí solo recuperamos de manera sucinta- es el que ofrece Ana Porrúa (2005). 
hiperconexión que le aportan los medios tecnológicos. En cualquier caso, su percepción del entorno inmediato aparece desrealizada hasta el punto en que el conocimiento de las palabras parece haberse perdido, extraviado bajo la atmósfera de reverberantes ensoñaciones que lo acompañan permanentemente, en un clima de asfixia que no sólo sofoca por el encierro tangible del espacio y los extremos oximorónicos de la incomunicación hiperconectada sino, sobre todo, porque el lector ve saturadas sus expectativas ante la inacción casi suicida del personaje, frente a la cual por momentos no queda otra interpretación posible que el absurdo:

\author{
Cómo se llama eso que cuelga de la pared, \\ cómo se llama eso que cubre la lámpara. \\ Rodeado de cosas sin nombre a mí también \\ me hubiera gustado empezar esto \\ con: de noche junto al fuego \\ pero acá \\ no hay, salvo en potencia, fuego \\ y eso que se divisa, una oscuridad \\ baldía sobre nosotros, a duras penas \\ puede ser llamada noche, nada \\ hace suponer el final de la transmisión nocturna \\ que ahora termina y deja \\ la pantalla nevada \\ trasladando a la penumbra del pasillo \\ la oscilación de un aire gris que no provoca \\ ninguna emoción salvo en las cosas. (Gambarotta, 2011a: 10)
}

La experiencia del ostracismo no resulta menos alienante que la que promueve la interacción en las calles de Buenos Aires. El aislamiento también desquicia y aparece potenciado por la negación constante a las intromisiones del mundo exterior, tanto es así que, para librarse de los ruidos vecinos, de las imágenes de los avisos publicitarios que irrumpen desde la ventana, el enunciador ensaya quimeras autosuficientes y tecnificadas para ejercer el control: "alcanza con bajar / la persiana para eliminar la escena" (Gambarotta, 2011: 15), expone en un momento de desvarío. En la apatía enfermiza del encierro, por un lado, se relajan las fronteras constitutivas de la subjetividad misma del protagonista: es aparentemente entrerriano, es aparentemente bisexual, es aparentemente conservador en materia política, entre otros "grises" que pulverizan la posibilidad de urdir percepciones orgánicas sobre el yo; mientras que, por otro, se subvierte el orden temporal y se traslada la persistente inacción hasta el sinsentido total, de donde sólo se puede ser auxiliado por la mano amiga del alcohol:

Hace un año la noche era igual y nada le asegura que, acostado, 


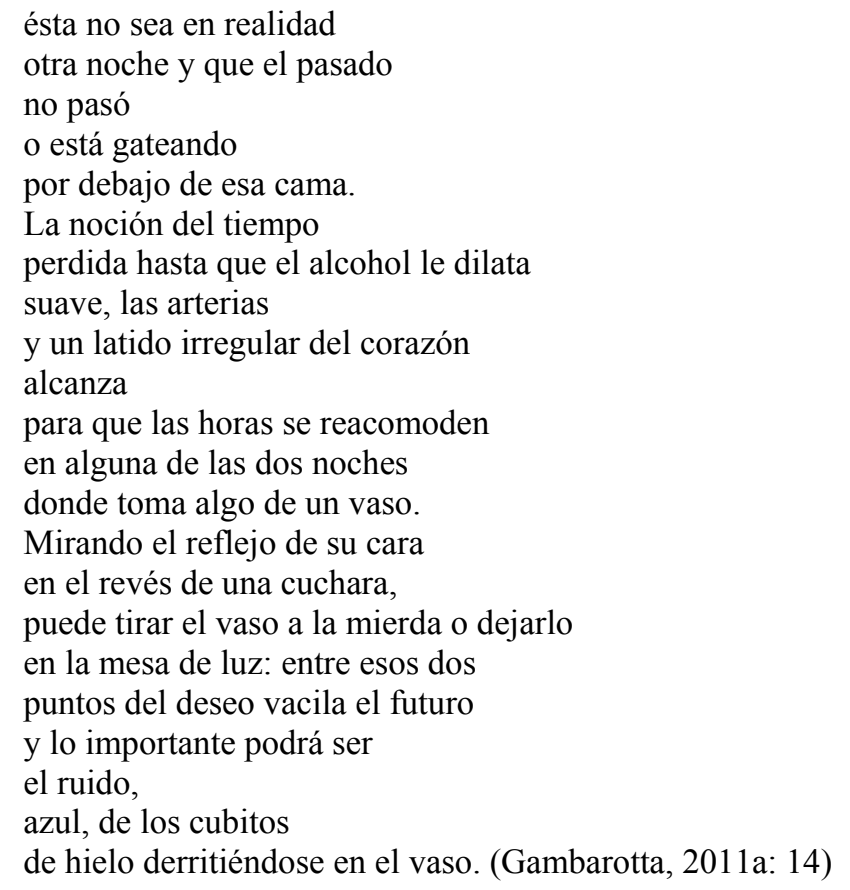

Desde la ventana censora de Cadáver, el fragmentarismo de las imágenes líricas montadas desde la lógica del zapping, con sus referencias al rock y las series televisivas, al manga japonés y los video games, ensambla una postal de la cultura popular contemporánea que irriga capilarmente la ciudad, enmarcada en la estética del trash -la basura urbana- y la violencia soterrada:

Escopetas recortadas en cartón, bidones

de nafta, plantas alicaídas, descompuestas, antes de lograr una forma madura bajo el toldo, vidrio molido en la carne picada, una vieja con el tobillo sangrándole bajo la media de nylon, el personal de limpieza en la planta baja de IBM, una cuadrilla de negros que se deja caer del camión para romper una calle. (Gambarotta, 2011a: 27)

La morguera estacionada

entre dos camiones del correo.

Olor a combustible cortado, el encargado de la playa que guía 
las maniobras de un auto.

Más allá, las bases navales,

las vías para los trenes de carga.

$\mathrm{Y}$ oficiales chuecos pidiendo

documentación a bolivianos.

Ah, que el gancho de esa grúa en desuso

me cace del paladar para poder

sobrevolar la escena.

De izquierda a derecha

dominante en el bajo cielo

gris gris gris analgésico. (Gambarotta, 2011a: 29)

Resignados ante la imposibilidad de cambio que la frustración del sujeto trasmina en los versos, la poesía de Gambarotta avanza sobre un pesimismo generalizado que transgrede los límites de la existencia individual en una ciudad como Buenos Aires. De modo que los íconos de la inacción -como el propio Cadáver-, la bestialización extendida por el mundo, la trivialización de las escalas axiológicas morales y la denuncia sobre la caducidad de los modelos culturales occidentales, sugieren la inutilidad -o, al menos, la incompetencia del presente- de seguir levantando un cosmos de sentidos mediante el cual sea posible aprehender el universo. Inmersa en un solipsismo desesperanzador, la poesía de Gambarotta ensaya entonces imágenes apocalípticas del abismo:

\author{
La ley seca \\ en un país mojado. Una paz \\ gelatinosa en un estado en bancarrota. \\ La ley seca en un país mojado, junto a la cama \\ los restos, las escamas en el plato, espinas \\ en la garganta, la membrana \\ cubriendo la máquina fusiladora \\ que trabaja en un idioma sin vértebras. (Gambarotta, 2011a: 93)
}

En momentos como el actual, cuando la crítica literaria argentina, a partir de categorías como "literatura postautónoma" (Ludmer, 2010), "literatura etnográfica" (Sarlo, 2007), "heteronomía literaria" (Garramuño, 2009) o "poesía testimonial" (Kamenszain, 2007), ${ }^{6}$ parece mirar con cierta desconfianza la emergencia de nuevas modalidades discursivas que subvierten, sin reparos, las convenciones genéricas y entrecomillan la -hasta ahora más o menos aceptada- función sociocultural asignada a la literatura, la poesía argentina contemporánea -tal como puede apreciarse en el breve recorrido que hemos trazado por la obra de dos autores- continua apostando,

\footnotetext{
${ }^{6}$ Un trabajo de síntesis, sumamente esclarecedor, que hace dialogar estas propuestas de conceptualización y sus categorías, puede leerse en Sandra Contreras (2010).
} 
con creces, por una tarea discursiva revulsiva y fundacional, que contrarresta los relativismos y la reasigna en su antiguo rol de develadora del mundo.

Así como la seducción y el temor ante las transformaciones de la vida urbana permitieron la emergencia de los versos de Baudelaire -fundacionales en la modernidad occidental- a partir de una nueva estimación de la literatura como redención de los avatares del tiempo, del mismo modo las expresiones poéticas de este nuevo siglo, que es percibido en muchos sentidos como una variable de pesadumbres contrastables, no escatima el valor trascendente de la palabra poética por su capacidad exhibitoria de la contingencia sociocultural. De este modo, y a pesar de su carga de escepticismo, Gambarotta sigue escribiendo poesía; mientras que Casas, por su parte, se encomienda, explícitamente, a la potencia del lenguaje adánico que da vida, que crea mediante el decir de la palabra poética:

\author{
Una lluvia finísima \\ cae en la calle \\ y emerge desde el suelo \\ un silencio precario. \\ De la ventana hacia afuera \\ los límites de mi lenguaje \\ crearon un mundo \\ que ya no me interesa. (Casas, 2010: 54)
}

En el mismo sentido puede leerse esta confianza plena en la lírica, al avanzar sobre los versos del breve poema "Good bye", otro texto epifánico de Casas, donde el lenguaje explora la potencia enunciativa de la condensación verbal y entroniza a la poesía -nuevamente- con los ropajes autosuficientes del insobornable vencedor de mediocres divinidades:

Benditos los que no tienen mitologías

y se refugian agazapados

bajo las lámparas del criadero;

benditos los que no saben que la muerte

da clases en todos lados

y se conforman con una palmada

y un plato de comida;

benditos los que entran en ese lugar

donde los significantes

le dan vuelta la cara a Dios. (Casas, 2010: 127)

El sujeto poético y la reconstrucción astillada de su subjetividad, que suele recobrarse con frecuencia en las apetencias satisfechas que el vagabundeo le reporta a los enunciadores líricos de Casas, frente a las adversidades del espacio extrañado que sobreimprime la aversión como otra forma de vinculación más traumática y 
menos conciliadora del yo con el entorno -tal como se patentiza en el sujeto yacente de Punctum de Gambarotta- delinean dos formas complejas de escenificación intimista del sujeto en la ciudad. De igual modo, las opciones retóricas empleadas resultan divergentes, en tanto que el registro poético aparece acompañado por la preeminencia del empleo del lenguaje coloquial en Casas, que parece instituirse como el más apropiado para el cosmos de su flânerie barrial; mientras que, en Gambarotta, se explotan las alternativas más insurrectas de una sintaxis abarrotada deudora del neobarroco hispanoamericano-, que deviene modulación precisa para la exasperación intimista y el malestar envolvente que sufre Cadáver. Anverso y reverso de una misma contingencia emotiva, la flânerie y el ostracismo perfilan la experiencia del sujeto en la vida actual de Buenos Aires, conducen sus instancias afectivas más desbordantes y apuestan por tendencias verbales que amojonan los signos inequívocos de este conflicto -paradójicamente íntimo- entre uno y los demás, entre el sujeto y la ciudad.

\section{BIBLIOGRAFÍA}

AA.VV.

2006 Tres décadas de poesía argentina. 1976-2006. Buenos Aires: Libros del Rojas.

BARTHES, Roland.

2012 La cámara lúcida. Nota sobre la fotografía. Buenos Aires: Paidós. BENJAMIN, Walter.

2012 El París de Baudelaire. Buenos Aires: Eterna Cadencia. BERMAN, Marshall.

1999 Todo lo sólido se desvanece en el aire. La experiencia de la modernidad. México: Siglo XXI.

CASAS, Fabián.

2010 Horla City y otros. Toda la poesía 1990-2010. Buenos Aires: Emecé.

CONTRERAS, Sandra.

2010 "En torno de las lecturas del presente", en Alberto Giordano (ed.), Los límites de la literatura. Rosario: Centro de Estudios de Literatura Argentina, Universidad Nacional de Rosario, pp. 133153.

CORNEJO POLAR, Antonio.

1994 Escribir en el aire. Ensayo sobre la heterogeneidad socio-cultural en las literaturas andinas. Lima: Editorial Horizonte.

GAMBAROTTA, Martín.

2009 Refrito. Santiago de Chile: La Calabaza del Diablo.

2011a Punctum. Buenos Aires: Mansalva/Vox. 
2011b Para un plan primavera. Bahía Blanca: Vox.

GARRAMUÑO, Florencia.

2009 La experiencia opaca. Literatura y desencanto. Buenos Aires: FCE. KAMENSZAIN, Tamara.

2007 "Testimoniar sin metáfora. (Los casos Washington Cucurto, Martín Gambarotta, Roberta Iannamico)", en La boca del testimonio. Lo que dice la poesía. Buenos Aires: Norma, pp. 117-162.

LUDMER, Josefina.

2010 "Lo que viene después. Una periodización literaria", Filología, año XLII, pp. 295-300.

MALLOL, Anahí.

2003 El poema y su doble. Buenos Aires: Simurg.

2009 "Cuando las cosas no son signos: la urbe de fin de siglo en la poesía NALLIM, Alejandra. argentina reciente", Cuadernos del Sur-Letras, n 39, pp. 189-209.

2012 "Por la cornisa urbana: literatura argentina del nuevo milenio", en Susana A. C. Rodríguez y Raquel Guzmán (coords.), La ciudad y sus representaciones. Arte y literatura a fin de milenio. Salta: Editorial de la Universidad Nacional de Salta, pp. 23-37.

ORTIZ, Mario.

2009 «Entre la "violencia" y el "lumpenaje": sujeto(s)/objetos(s) en la poesía argentina del siglo XX (breve aproximación histórica)», Cuadernos del Sur-Letras, $\mathrm{n}^{\circ}$ 34, pp. 89-114.

PORRÚA, Ana.

2005 "Punctum: sombras negras sobre una pantalla", Boletín del Centro de Estudios de Teoría y Crítica Literaria, $\mathrm{n}^{\mathrm{o}}$ 12, pp. 102-112

2009 "Subjetividad y mirada en la poesía argentina reciente", Cuadernos del Sur-Letras, no 34, pp. 15-38.

RAMA, Ángel.

1985a "La modernización literaria latinoamericana (1870-1910)", en La crítica de la cultura en América Latina. Caracas: Biblioteca Ayacucho, pp. 82-96.

1985b Las máscaras democráticas del modernismo. Montevideo: Fundación Ángel Rama.

RAMOS, Julio.

1989 Desencuentros de la modernidad en América latina. Literatura y politica en el siglo XIX. México: FCE.

SARLO, Beatriz.

2007 "La novela después de la historia. Sujetos y tecnologías", en Escritos sobre literatura argentina. Buenos Aires: Siglo XXI, pp. 471-482. 
2009 La ciudad vista. Mercancías y cultura urbana. Buenos Aires: Siglo XXI.

STEIMBERG, Oscar.

2011 "Punctum: un posfacio", en Martín Gambarotta, Punctum. Buenos Aires: Mansalva/Vox, pp. 99-108. 